\title{
Dorsal penile frenulum a rare congenital abnormality
}

\author{
A. M. Mukendi ${ }^{*}$ and S. W. Doherty
}

\begin{abstract}
Background: Dorsal penile frenulum is noted to be an extremely rare congenital penile abnormality. Only two cases have been reported in the literature.

Case presentation: A 31-year-old male was involved in a motor vehicle accident and sustained a pelvic fracture and a scrotal laceration which was the main reason for urology consult. Genital examination revealed a circumcised penis, the presence of two frenula and a right scrotal laceration. Scrotal laceration was cleaned and closed. Orthopaedic surgeon took over the patient for the pelvic fracture.
\end{abstract}

Conclusion: This is the third reported case of a dorsal penile frenulum incidentally found in a circumcised male and completely asymptomatic. A brief review of relevant embryology and anatomy is herein discussed.

Keywords: Penile frenulum, Congenital penile abnormality, Penile torsion, Dorsal frenulum, Dyspareunia, Circumcision

\section{Background}

Dorsal penile frenulum not associated with penile torsion is a rare penile anomaly [1]. Only two cases have been reported in the literature in 1997 and in 2016. This is the third case report unlike the other two, is completely asymptomatic. The most common associated symptom reported in the literature is dyspareunia. The first ever reported case had pains on foreskin retraction. We herein present another dorsal penile frenulum and discuss relevant embryology and anatomy.

\section{Case presentation}

A 31-year-old male was brought to our trauma emergency unit after being in a motor vehicle accident. He sustained a pelvic fracture and a right scrotal laceration. There was no bladder injury. The orthopaedic surgeon was called for his pelvic fracture and the urologist on call for the scrotal laceration. Relevant genital history was taken after penile examination and revealed patient's awareness of having what he described as a second cord

*Correspondence: alainmwamba2006@yahoo.fr

Department of Urology, Chris Hani Baragwanath Academic Hospital, University of the Witwatersrand, Chris Hani Road/Soweto, Johannesburg, South Africa on the dorsal aspect of the penis attached to the glans on one end and to the foreskin on the other end way before the circumcision, no history of balanoposthitis in childhood and no history of dyspareunia. He had a traditional circumcision at 10 years of age not complicated by any infection or wound healing abnormalities. On examination, there were two bands connecting the glans to distal penile shaft one on the dorsal aspect and the other one on the ventral aspect. There was no penile torsion. The rest of the penis was normal with the external urinary meatus at its normal position and a size 16-F Foley's catheter already inserted by the trauma team (Figs. 1, 2, 3). A 4-cm-long, $1.5 \mathrm{~cm}$ wide and $3 \mathrm{~mm}$ deep oval right scrotal laceration was noted. Testes were not exposed and felt normal. Scrotal laceration was cleaned and closed under local anaesthesia with chromic 3.0. Patient was admitted in the orthopaedic ward for management of his pelvic fracture.

\section{Discussion}

Dorsal penile frenulum not associated with penile torsion is an unusual congenital penile anomaly [1]. Described symptomatology in the literature includes pains on foreskin retraction and dyspareunia $[1,2]$. The most important finding in this case is the presence of 


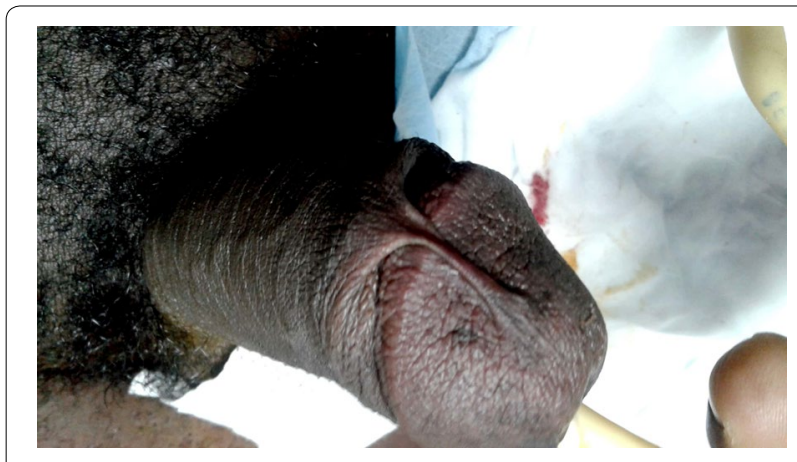

Fig. 1 Superior view of the dorsal frenulum

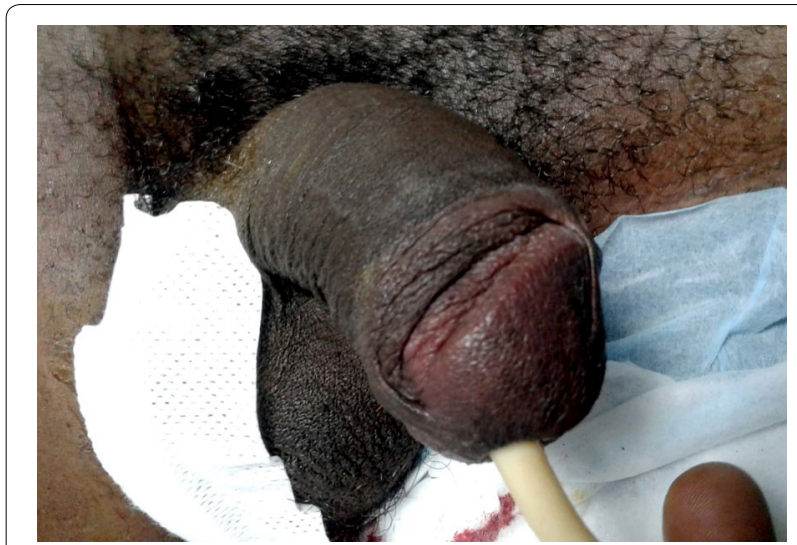

Fig. 2 Lateral view of both dorsal and ventral frenulum

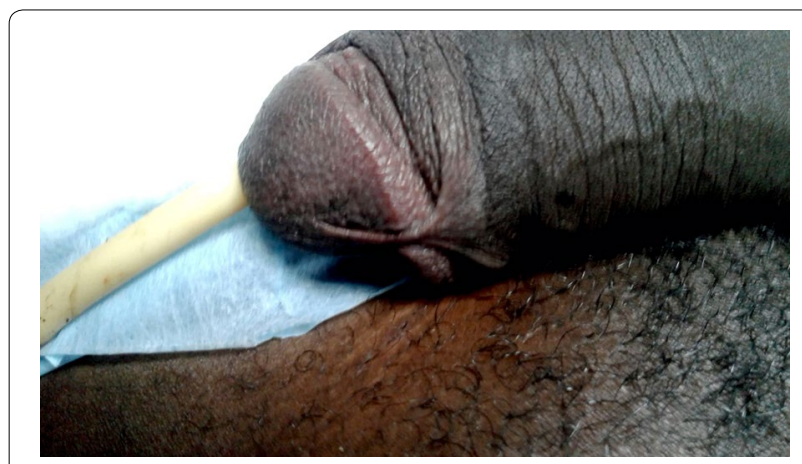

Fig. 3 Dorsal frenulum

both the dorsal and ventral frenulum in a traditionally circumcised male associated with the absence of any symptoms reported in the other two preceding case reports. Fascinatingly, the first reported case had only a dorsal frenulum and the normal ventral frenulum was absent; the second reported case and our case had both a dorsal and ventral frenulum. However, they all have in common this rare penile frenulum abnormality not associated with penile torsion.

The prepuce constitutes the anatomical covering of the glans penis. Its embryologic development is related to that of the frenulum [1]. At 8 weeks post-conception, the ectoderm begins to develop into the penile skin and prepuce [3]. The prepuce in particular is formed by reduplication of the distal penile ectoderm in the third month of intrauterine life $[1,2]$. The preputial sac is then formed as a result of separation of the prepuce from the glans. The frenulum is formed from the persistent residual adhesions of ectoderm to the glans penis on the ventral aspect $[1,2]$. Singla et al. [1] postulated that the dorsal frenulum may probably result from residual adhesions on the dorsal side. In our case, residual adhesions of the ectoderm on both dorsal and ventral aspects of the glans may justify the presence of two frenula.

The prepuce is a pentalaminar structure composed of an outer glabrous skin, dermis, dartos muscle, lamina propria and a squamous mucosal epithelium [4]. This mucosal epithelium is common to the glans penis and the inner mucosal lining of the prepuce [4]. The frenulum preputii is composed of mesenchymal tissue covered by an epithelium that unites the prepuce to the ventral region of the glans [5].

Penile innervation consists of the dorsal, cavernosal and perineal nerves. Dorsal nerves arise from the pudendal nerves and travel within Buck's fascia to supply sensation to the penile skin [3]. The prepuce has somatosensory innervation from the dorsal nerve of the penis and branches of the perineal nerve. This unique innervation of the prepuce establishes its function as an erogenous tissue [4]. Arterial blood supply to penile skin derives from two separate origins. External pudendal artery branches supply the dorsal and lateral aspects of the penis, branches of the internal pudendal artery the ventral aspect of the penis and the scrotum via the posterior scrotal artery. The penile skin drains via the superficial dorsal vein, which drains into the saphenous vein via the superficial external pudendal veins [3]. Lymphatic drainage from the glans and foreskin drains into the inguinal lymph nodes. Some lymphatic drainage is to the presymphyseal lymph nodes and to the lateral lymph nodes of the external iliac lymphatics [6].

\section{Conclusion}

This is the third reported case of dorsal penile frenulum incidentally found in a traditionally circumcised male and completely asymptomatic. An assumption can be made that circumcision without release of the dorsal frenulum is another symptomatic treatment option. Taking into consideration cultural beliefs, the clinician should be able 
to offer circumcision and/or frenuloplasty to those who are pro-circumcision and frenuloplasty alone to those against it.

\section{Authors' contributions}

AMM involved in substantial contributions to conception of the case report; acquisition of data; drafting of the manuscript; critical revision for important intellectual content; and approval of final version. SWD involved in substantial contributions to critical revision and approval of final version. Both authors read and approved the final manuscript.

\section{Acknowledgements}

Not applicable.

\section{Competing interests}

The authors declare that they have no competing interests.

\section{Availability of data and materials}

Not applicable.

\section{Consent for publication}

Written informed consent was obtained from the patient for publication of this manuscript and accompanying pictures. A copy of the written consent is available for review by the Editor-in-Chief of this journal.

\section{Ethics approval and consent to participate}

The Wits Human Research Ethics Committee approved this study (reference: M180990).
Funding

None.

Received: 17 October 2019 Accepted: 29 October 2019

Published online: 08 November 2019

\section{References}

1. Singla SL, Garg P, Bishnoi PK, Singh B (1997) Dorsal penile frenulum. Urol Int 59(1):55-56

2. Arora B (2016) Dorsal penile frenulum: a rare developmental abnormality. Int J Case Rep Imag 7(5):311-313

3. Yiee JH, Baskin LS (2010) Penile embryology and anatomy. Sci World J TSW Urol 8:1174-1179. https://doi.org/10.1100/tsw.2010.112

4. Cold CJ, Taylor JR (1999) The prepuce. Br J Urol 83(Suppl. 1):34-44

5. Favorito LA, Balassiano CM, Costa WS, Sampaio FJB (2012) Development of the human foreskin during the fetal period. Histol Histopathol 27:1041-1045. https://doi.org/10.14670/HH-27.1041

6. Ellsworth PI, Gest TR (2017) Penis anatomy. Medscape2017. https://emedi cine.medscape.com/article/1949325-overview

\section{Publisher's Note}

Springer Nature remains neutral with regard to jurisdictional claims in published maps and institutional affiliations.

\section{Submit your manuscript to a SpringerOpen ${ }^{\circ}$ journal and benefit from:}

- Convenient online submission

- Rigorous peer review

- Open access: articles freely available online

High visibility within the field

- Retaining the copyright to your article

Submit your next manuscript at $\boldsymbol{\nabla}$ springeropen.com 